\title{
Response to cold and abnormalities of nerve conduction velocity in hand-arm vibration syndrome
}

\author{
V Brezinova, D N Quinton
}

The hand-arm vibration syndrome (HAVS) contains both vascular (vibration induced white finger (VIWF)) and sensorineural components. Although a close link between the two has been found in some studies, ${ }^{1}$ others indicate that vasomotor and neuropathic dysfunction develop independently. ${ }^{2}$ We have found support for the second view while comparing the results of a cold provocation test with electrophysiological nerve conduction velocity (NCV) studies.

\section{Material and methods \\ We examined twenty metal workers (all men, age range 37-64, mean 49) who used pneumatic equip- ment and were claiming industrial compensation. Their professional exposure to vibration was 25 (standard deviation (SD) eight) years. Duration of symptoms averaged eight (SD six) years. A clinical examination was performed (by DNQ) and a provocation test was carried out by immersing subjects' hands in iced water for five minutes, recording subjective pain and capillary response with the Lewis Prusik nail pressure test. ${ }^{3}$ In a different session NCV studies were performed bilaterally (by VB) on motor and sensory branches of the median and ulnar nerves in the hands and forearms starting on the side with more prominent subjective symp- toms. The NCV studies, first performed on warm hands $\left(>30^{\circ} \mathrm{C}\right)$, were repeated after cooling the hands in iced water for five minutes. A Medelec Mystro machine and the conventional NCV tech- nique with antidromic recording of sensory nerve action potentials were used.}

The clinical syndrome was scored on both the Taylor-Pelmear (TP) and the Stockholm Workshop (SW) scales. Pain during the first cold test and the capillary changes were scored semiquantitatively on a four point scale. Also the amount of subjective clinical symptoms was rated separately for the median and ulnar nerve territory in each hand. The results of NCV studies at normal temperature were

\footnotetext{
Department of Clinical Neurophysiology and Department of Accident and Emergency, Leicester Royal Infirmary, Leicester, UK

V Brezinova, D N Quinton
}

converted to composite scores, adding one point for each abnormal value found in conduction velocity or amplitude of sensory and mixed nerve action potentials, separately for the median and ulnar nerve in each arm, as well as for all four nerves together. The NCV change after the second cold test was expressed as the difference from the data obtained before cooling. The skin temperature was measured in each hand (palm) just before the NCV testing, to register the partial rewarming that occurred in the hand examined second.

Non-parametric tests, and two tailed $p$ values were used for statistical evaluations.

\section{Results}

The HAVS score averaged 2.5 (SD 0.7 ; range $1-4$ ) on the TP scale, and 1.8 (SD 0.8 ; range $1-3$ ) on the SW scale. A positive correlation with the duration of clinical symptoms was found for both ratings ( $p<0.02$ for TP scale; $p<0.01$ for SW scale). The dominant hand was more likely to show worse clinical symptoms (Fisher's test, $p<0.05$ ). During the first cold water challenge 13 patients $(65 \%)$ complained of pain and $10(50 \%)$ showed a positive or very positive nail pressure test. In the NCV studies at normal temperature no abnormality or composite abnormal score less than or equal to five were found in nine patients (three and six patients respectively). A composite abnormal score less or equal to 10 was obtained in eight patients $(40 \%)$ and more than 10 in three patients $(15 \%)$. Of the 128 abnormal values recorded $101(79 \%)$ concerned reduced amplitude of sensory or mixed nerve action potentials and $27(21 \%)$ slowing of motor or sensory NCV. After the second cold water immersion the skin temperature was decreased on average by $11^{\circ} \mathrm{C}$ (SD $3 \cdot 0$, range $5 \cdot 0-17 \cdot 3$ ) in the hand tested immediately after cooling (the hand with more prominent clinical symptoms), and by $7^{\circ} \mathrm{C}$ (SD 2, range $1 \cdot 1-10 \cdot 6)$ in the other hand. The NCV slowing for the median sensory nerve action potential from digit II (always the first to be examined) averaged $11.4(\mathrm{SD} 6.0) \mathrm{m} / \mathrm{s}$ in the hand with the greater skin temperature drop; the NCV slowing for the ulnar sensory nerve action potential from digit $\mathrm{V}$ in the same hand averaged $11.4($ SD $4 \cdot 1) \mathrm{m} / \mathrm{s}$.

The data obtained in 10 patients with positive or very positive nail pressure tests were compared with 


\begin{tabular}{|c|c|c|c|}
\hline & $\begin{array}{l}\text { Positive cold test } \\
(n=10)(\text { mean }(S D))\end{array}$ & $\begin{array}{l}\text { Negative cold test } \\
(n=10)(\text { mean }(S D))\end{array}$ & p Value \\
\hline $\begin{array}{l}\text { Pain during cold test (No) } \\
\text { SW score } \\
\text { Abnormal NCV score (total) } \\
\text { Abnormal NCV (median nerve score) } \\
\text { Abnormal NCV (ulnar nerve score) } \\
\text { NCV decrease in cold }\left(\mathrm{m} / \mathrm{s} \text { per }{ }^{\circ} \mathrm{C} \text {; digit II) }\right.\end{array}$ & $\begin{array}{l}9 \\
2 \cdot 0(0 \cdot 8) \\
4 \cdot 2(4 \cdot 8) \\
2 \cdot 9(3 \cdot 8) \\
1 \cdot 3(1 \cdot 6) \\
1 \cdot 3(0 \cdot 6)\end{array}$ & $\begin{array}{l}4 \\
1 \cdot 6(0 \cdot 7) \\
8 \cdot 6(3 \cdot 2) \\
6 \cdot 1(3 \cdot 3) \\
2 \cdot 5(1 \cdot 8) \\
1 \cdot 0(0 \cdot 5)\end{array}$ & $\begin{array}{l}<0 \cdot 05^{\star} \\
\text { NS }{ }^{\dagger} \\
<0 \cdot 05^{\dagger} \\
<0 \cdot 10 \dagger \\
\text { NS } \dagger \\
\text { NS } \dagger\end{array}$ \\
\hline
\end{tabular}

^Fisher's exact probability test.

$\succ$ Mann-Whitney U test, two tailed.

$\mathrm{NS}=$ Non-significant .

those in 10 patients showing no or only equivocal vascular changes (table). The patients with an abnormal vascular response to cold were more likely to complain of pain during the cold provocation test, but they had less abnormal findings in NCV studies at normal temperature. No difference was found between the two groups in the amount of NCV slowing per $1^{\circ} \mathrm{C}$ decrease in skin temperature. The difference in the SW score, higher in the patients with abnormal vascular response to cold, was not significant, nor was a similar difference in TP score. A trend $(\mathrm{p}<0 \cdot 1)$ was found in age distribution, the patients with a positive cold test being on average six years younger than the other group.

A clinical suspicion of carpal tunnel syndrome was raised in three patients and that of an additional cervical radiculopathy in two patients. An electrical abnormality suggesting a carpal tunnel syndrome was found three times, very pronounced in one patient suspected clinically, and mild in two patients, apparently subclinical. In four more patients mild electrical signs of an ulnar nerve lesion at the elbow were found. All three patients with electrical features of carpal tunnel syndrome were in the group with normal response to cold, but the four patients with ulnar nerve dysfunction were equally divided between the two groups. The separate scores for clinical symptoms found for the median and ulnar nerve in each hand failed to show a significant correlation with the corresponding electrophysiological scores.

\section{Discussion}

The lack of a positive correlation between the abnormal vascular response to cold and the abnormal NCV findings at normal temperature in our patients would fit with the prevailing opinion ${ }^{4}$ that the vascular and neuropathic components of the HAVS are separate entities. Also no significant effect of vascular dysfunction on the degree of cold induced NCV slowing was found. In both groups of patients the average decrement of $\mathrm{NCV}$ per ${ }^{\circ} \mathrm{C}$ decrease in skin temperature $(1.3 \mathrm{~m} / \mathrm{s}$ and $1.0 \mathrm{~m} / \mathrm{s}$ respectively) was smaller than the expected rate of $2 \mathrm{~m} / \mathrm{s}$ slowing per ${ }^{\circ} \mathrm{C}$ recorded in normal subjects. ${ }^{5}$ This might be partly explained by a relatively small reduction in skin temperature in some patients and a less prominent effect of temperature on the NCV in that range. ${ }^{6}$ In the present study a slowing of NCV at normal skin temperature represented a relatively small proportion $(21 \%)$ of the abnormal findings, and thus an electrical pattern typical of carpal tunnel syndrome was rather rare $(15 \%)$. By contrast, a relatively small incidence of abnormal response to cold $(11 \%)$ was reported in a study showing a high incidence of carpal tunnel syndrome $(63 \%) .^{7}$ Most of the abnormal electrophysiological findings in our patients consisted of a reduction in amplitude of the sensory and mixed nerve action potentials, suggesting an axonal dysfunction or axonal loss as well as a degree of demyelination. Such findings, if not explained by a proximal cause-for example, radiculopathy-might reflect the vibration induced changes in peripheral nerve fibres found in histopathological studies. ${ }^{8}$

Requests for reprints to: Mr D N Quinton, FRCS, Department of Accident and Emergency, Leicester Royal Infirmary, Infirmary Square, Leicester LE1 5WW.

1 Araki S, Yokoyama K, Aono H, Murata K. Determination of the distribution of nerve conduction velocities in chain saw operators. Br J Ind Med 1988;45:341-4.

2 Harada N, Matsumoto T. Various function tests on the upper extremities and the vibration syndrome. In: Taylor W, Brammer AJ, eds. Vibration effects on the hand and arm in industry. New York: Wiley and Sons, 1983:71-6.

3 Lewis T. Vascular disorder in the limbs. London: Macmillan, 1949.

4 Taylor $W$. Hand-arm vibration syndrome: a new clinical classification and an updated British standard guide for hand transmitted vibration. Br J Ind Med 1988;45:281-2.

5 Buchthal F, Rosenfalck A. Evoked action potentials and conduction velocity in human sensory nerves. Brain Res 1966;3: $1-122$.

6 Todnem K, Knudsen G, Riise T, Nyland H, Aarli JA. The nonlinear relationship between nerve conduction velocity and skin temperature. J Neurol Neurosurg Psychiatry 1989;52:497-501.

7 Boyle JC, Smith NJ, Burke FD. Vibration white finger. $J$ Hand Surgery (British) 1988;13B:171-6.

8 Ho ST, Yu HS. Ultrastructural changes of the peripheral nerve induced by vibration: an experimental study. $\mathrm{Br} \mathrm{J}$ Ind Med 1989;46:157-64.

Accepted 12 November 1990 